Supporting Information for

\title{
Chain Alignment of a Rigid Ring Polymer in Lyotropic Liquid Crystal Phase: Cyclic Amylose Tris(n-butylcarbamate) in Tetrahydrofuran and Ethyl Lactate
}

\author{
Daigo Kabata, ${ }^{\dagger}$ Akiyuki Ryoki, ${ }^{\dagger,}{ }^{\dagger}$ Shinichi Kitamura, ${ }^{\S}$ and Ken Terao ${ }^{*}, \dagger$ \\ $†$ Department of Macromolecular Science, Graduate School of Science, Osaka University, 1-1 \\ Machikaneyama-cho, Toyonaka, Osaka 560-0043, Japan \\ †Department of Polymer Chemistry, Graduate School of Engineering, Kyoto University, Katsura, \\ Kyoto 615-8510, Japan
}

$\S$ Center for Research and Development of Bioresources, Organization for Research Promotion, Osaka Prefecture University, 1-2, Gakuen-cho, Naka-ku, Sakai, 599-8570, Japan

* Corresponding author. E-mail address: terao.ken.sci@osaka-u.ac.jp

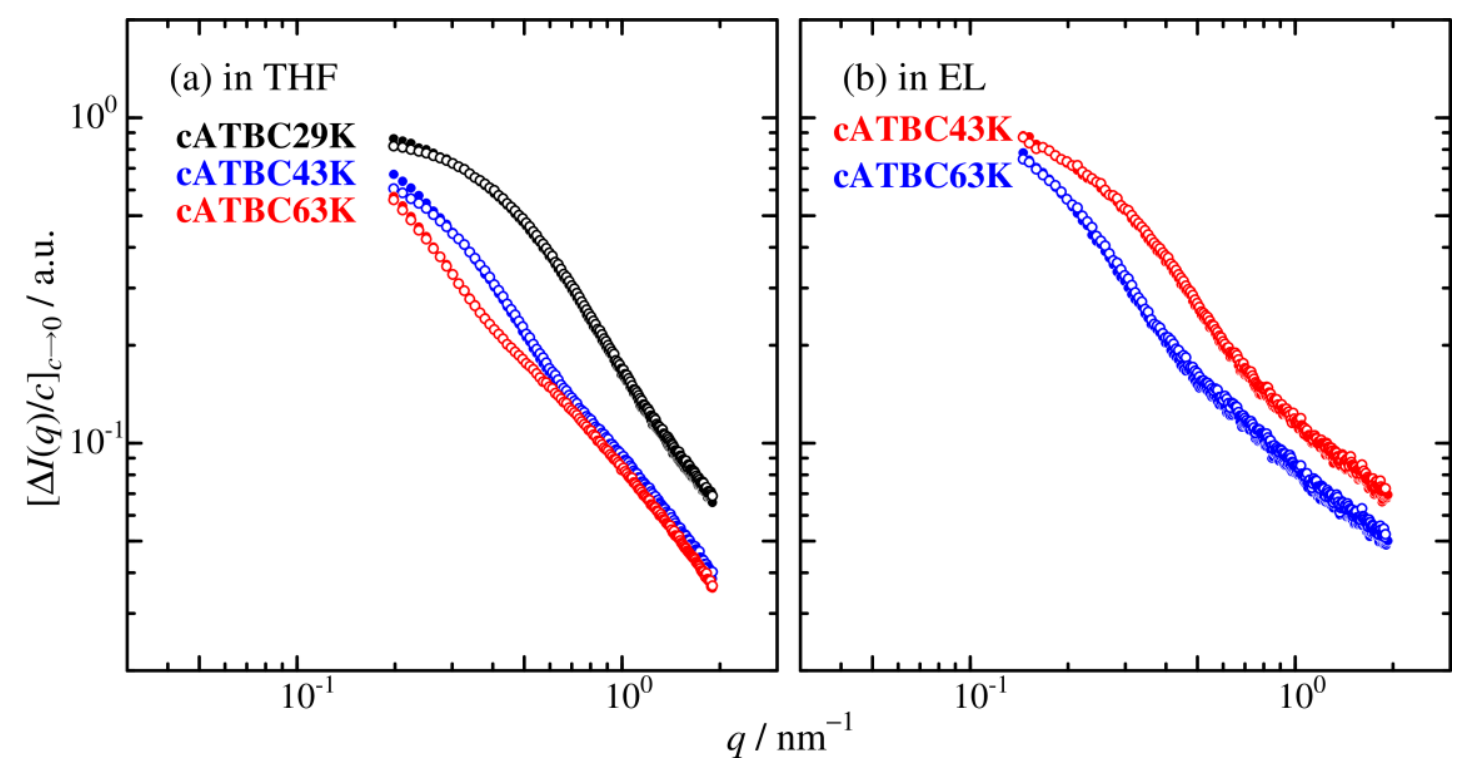

Figure S1. Double logarithmic plots for the excess SAXS scattering intensity $[\Delta I(q) / c]_{c \rightarrow 0}$ versus $q$ for the indicated cATBC samples in THF (a) and in EL (b) at $25{ }^{\circ} \mathrm{C}$. Unfilled symbols denote the data for the recovered samples from the liquid crystalline phase. Filled symbols (almost behind the unfilled symbols) are the data for the fresh solutions. 


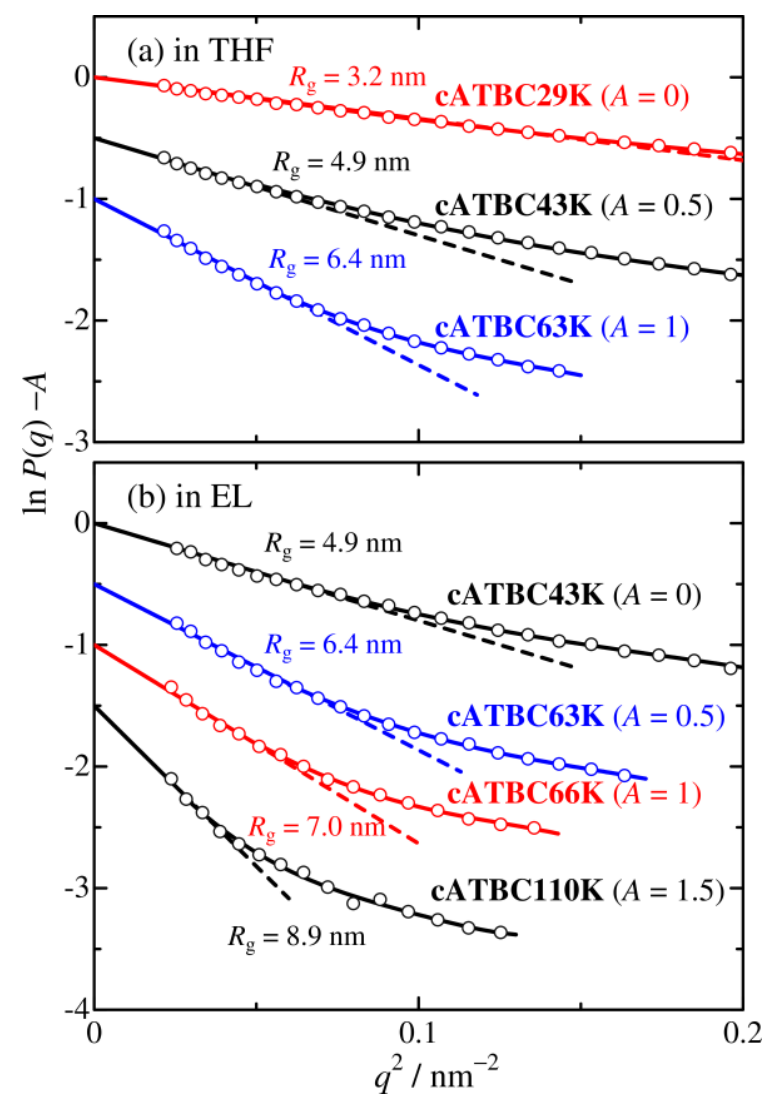

Figure S2. Guinier plots for the indicated cATBC samples in THF (a) and in L-ethyl lactate (EL) (b) at $25^{\circ} \mathrm{C} . \quad P(q), q$, and $A$ are the form factor, the magnitude of the scattering vector, and the shift factor, respectively. The dashed lines indicate the initial slope to estimate the radius of gyration $R_{\mathrm{g}}$.

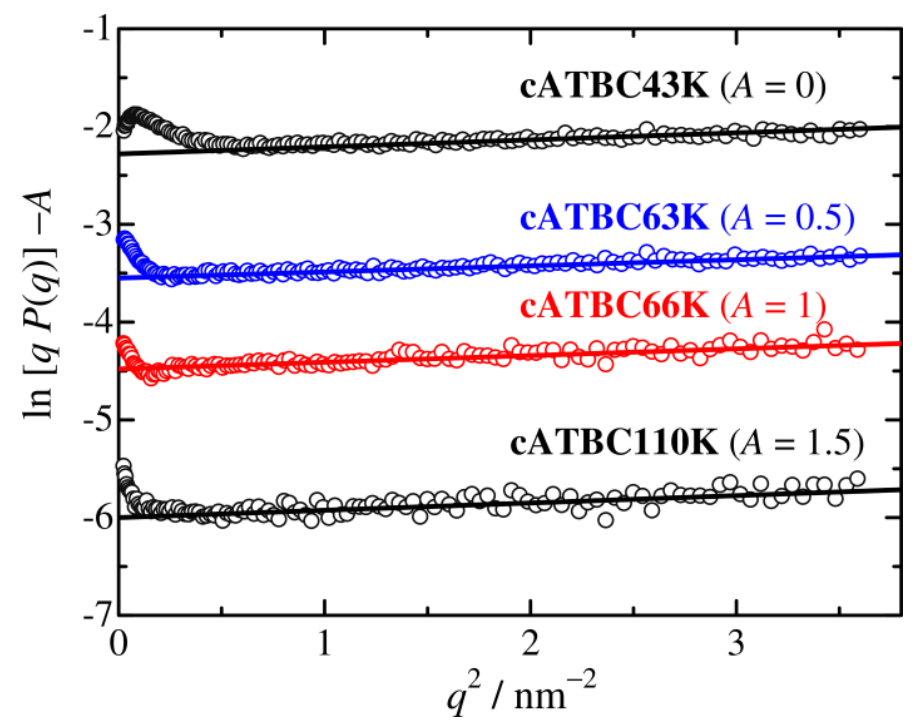

Figure S3. Cross-sectional plots based of the equation $\left[P(q) \propto \exp \left(-q^{2} d^{2} / 16\right)\right]$ for the indicated cATBC samples in EL at $25^{\circ} \mathrm{C}$. Solid lines are the slope with the $d^{2}$ values of -1.2 , $-1.0,-1.1$, and $-1.2 \mathrm{~nm}^{2}$ for сATBC43K, сАТВС63К, сАТВС66K, and сАТВС110K, respectively. 

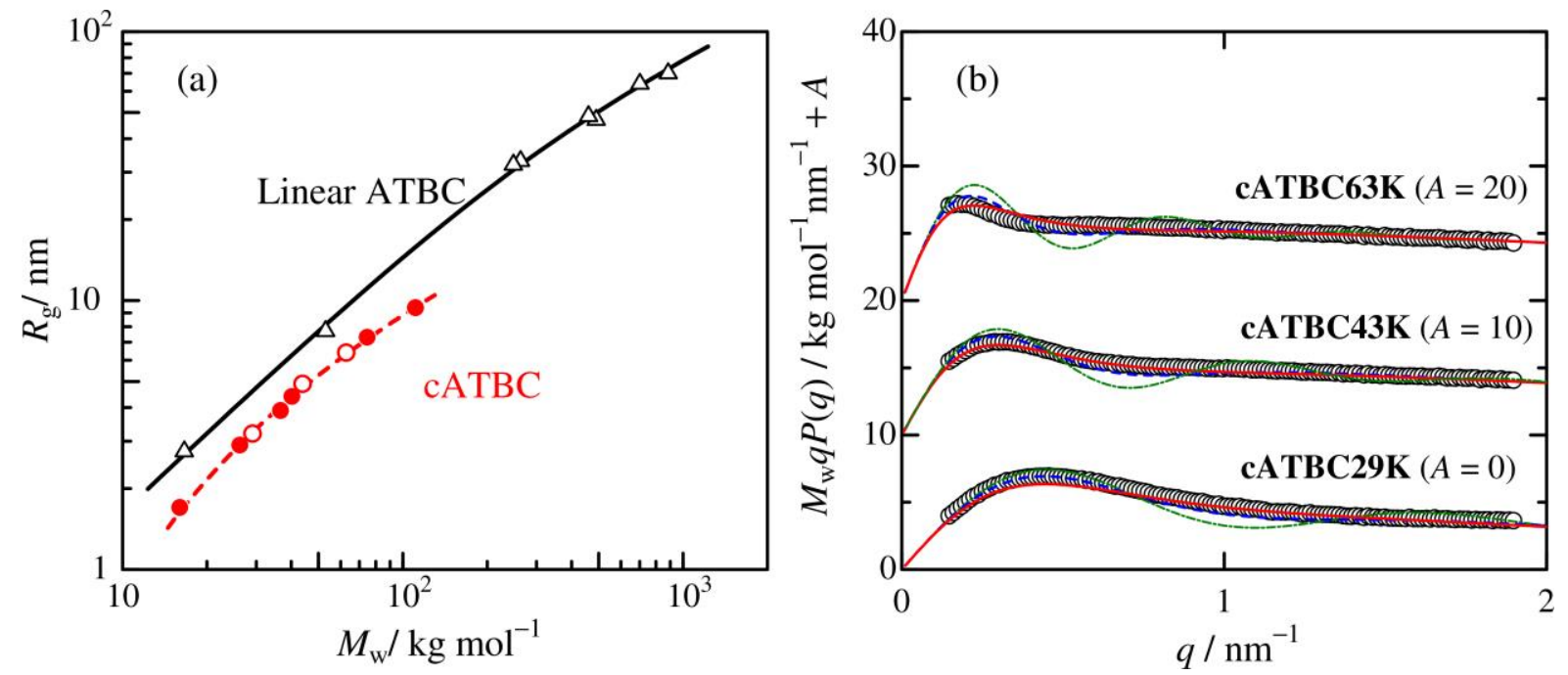

Figure S4. Dimensional properties of cATBC in dilute THF solution at $25{ }^{\circ} \mathrm{C}$. (a) Weight-average molar mass $M_{\mathrm{w}}$ dependence of the radius of gyration $R_{\mathrm{g}}$ (unfilled circles) with the previous data for cATBC (filled circles) ${ }^{1}$ and those for linear ATBC (triangles). ${ }^{2}$ (b) Reduced Holtzer plots for the indicated cATBC samples. Curves, theoretical values for wormlike rings of $h_{\text {ring }}=0.26,0.28$, and $0.28 \mathrm{~nm}$ and $L_{\mathrm{k}, \text { ring }}=(50),(25)$, and (14) nm, for САТВС63K, сАТВC43K, and сАТВC29K, respectively, with $Ð=1.00$ (dot-dashed green), 1.10 (dashed blue), and 1.30 (solid red). The values of $L_{\mathrm{k}, \text { ring }}$ cannot be determined from the curve fitting procedure because the theoretical values are not enough different from the rigid limiting value.

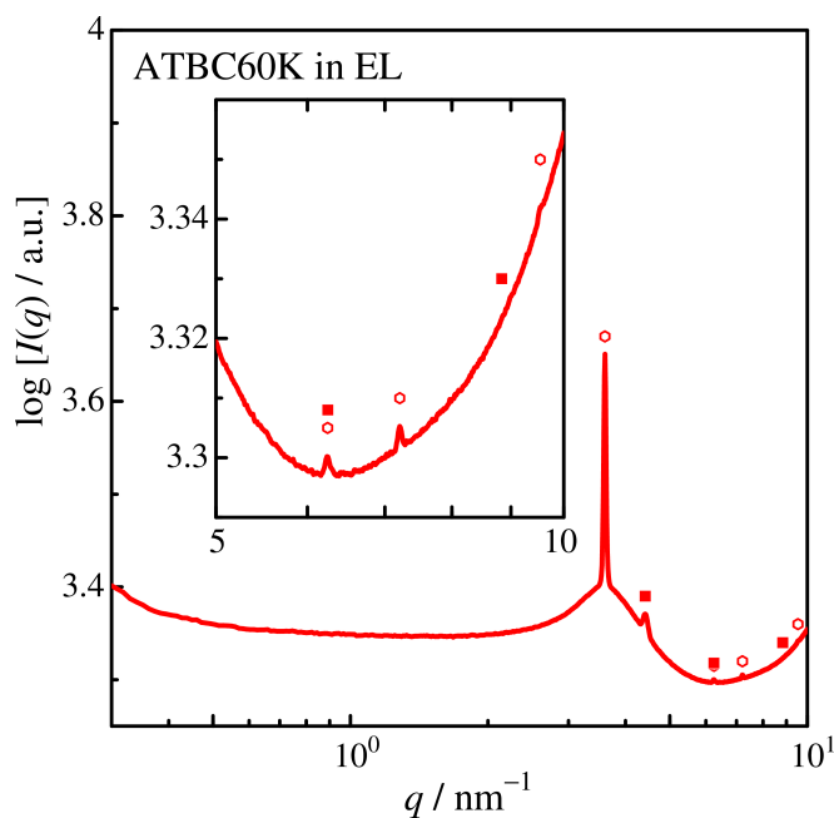

Figure S5. Plots of scattering intensity $I(q)$ versus $q$ for ATBC60K $\left(c=0.49 \mathrm{~g} \mathrm{~cm}^{-3}\right)$ in EL at $25{ }^{\circ} \mathrm{C}$. 


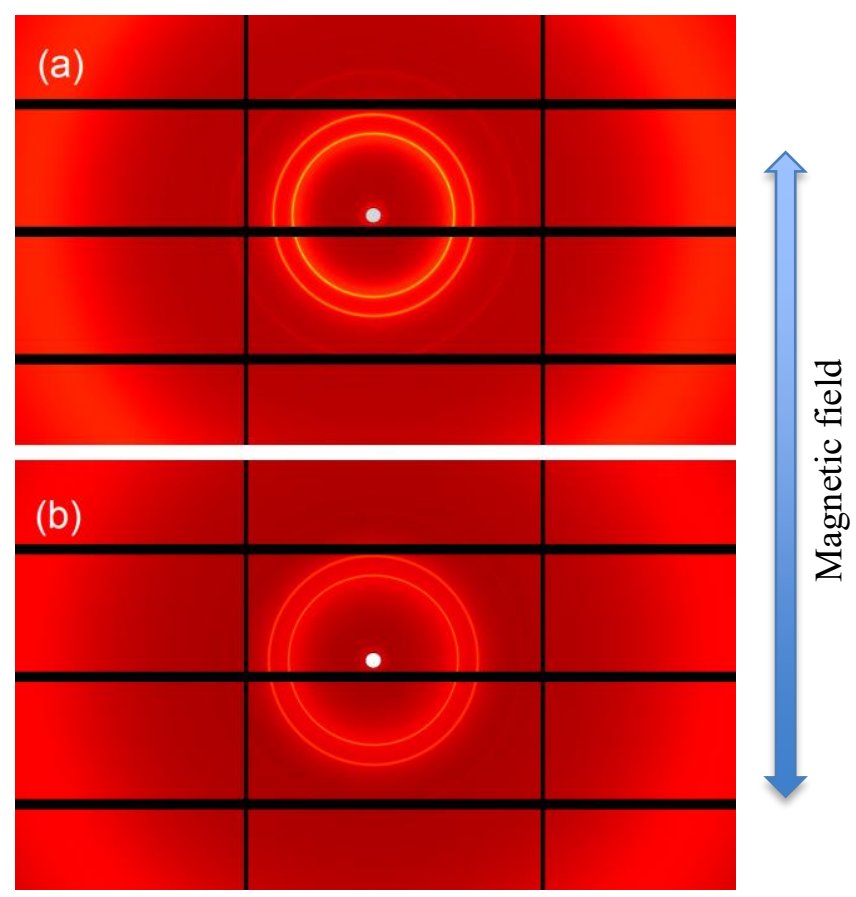

Figure S6. Two-dimensional scattering profiles for cATBC110K in THF $(c=0.484 \mathrm{~g}$ $\left.\mathrm{cm}^{-3}\right)$ and in $\operatorname{EL}\left(c=0.528 \mathrm{~g} \mathrm{~cm}^{-3}\right)$ at $25^{\circ} \mathrm{C}$. The camera length was $420 \mathrm{~mm}$. Magnetic field was applied prior to measurement.

\section{References}

1. Terao, K.; Shigeuchi, K.; Oyamada, K.; Kitamura, S.; Sato, T., Solution Properties of a Cyclic Chain Having Tunable Chain Stiffness: Cyclic Amylose Tris(n-butylcarbamate) in $\Theta$ and Good Solvents. Macromolecules 2013, 46 (13), 5355-5362.

2. Terao, K.; Murashima, M.; Sano, Y.; Arakawa, S.; Kitamura, S.; Norisuye, T., Conformational, Dimensional, and Hydrodynamic Properties of Amylose Tris(n-butylcarbamate) in Tetrahydrofuran, Methanol, and Their Mixtures. Macromolecules 2010, 43 (2), 1061-1068. 